\title{
Retraction Note to: Optimization of marine biological sediment and aerobics training mode based on SVM
}

\author{
Meiyun Liu ${ }^{1}$
}

Published online: 4 November 2021

(c) Saudi Society for Geosciences 2021

Retraction Note to: Arabian Journal of Geosciences (2021) 14: 1503 https://doi.org/10.1007/s12517-021-07838-1

The Editor-in-Chief and the Publisher have retracted this article because the content of this article is nonsensical. The peer review process was not carried out in accordance with the Publisher's peer review policy. The author has not responded to correspondence regarding this retraction.

The original article can be found online at https://doi.org/10.1007/ s12517-021-07838-1.

Meiyun Liu

lmyxiang@163.com

1 School of Physical Education, North University of China,

Taiyuan, Shanxi, China 